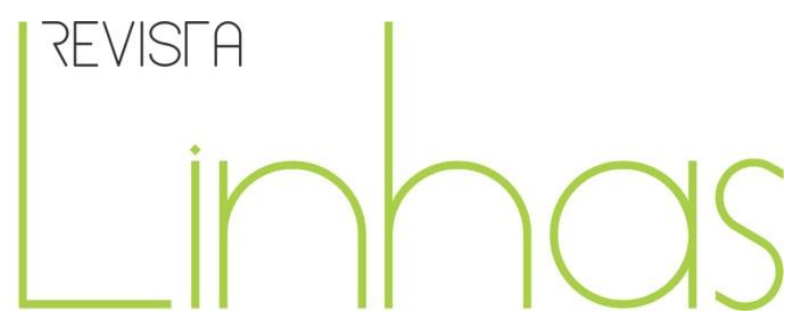

\title{
A institucionalização dos grupos escolares no Maranhão
}

\section{Resumo}

Este trabalho apresenta a história dos grupos escolares maranhenses implantados a partir de 1903, focalizando o seu processo de institucionalização, o ensino, os exames, a frequência escolar, a fiscalização, os deveres e regras que deveriam ser obedecidos por alunos e professores. Explica os principais aspectos estruturais que determinaram a extinção dessas escolas em 1912. A metodologia utilizada está baseada na pesquisa bibliográfica, priorizando os estudos de Vidal (2006, 2007), Faria Filho (2006, 2007), Souza (2006, 2007, 2008, 2010), Motta (2006) e Saldanha (1992); em segundo lugar, recorreu-se à pesquisa documental a partir da identificação, seleção, análise e descrição dos documentos da Escola Normal (19031912), da Secretaria Geral da Instrução Pública Maranhense (19061910); relatórios dos Inspetores e Delegados da Educação (1903-1911), ofícios, notas fiscais de compra de materiais, fotografias, relatórios de Governadores do Estado (1903-1912), lista de frequência e de notas de alunos e análise do Regimento Interno dos Grupos Escolares, a fim de compreender como foi instituída a organização do trabalho pedagógico, o currículo, o estabelecimento de horário de aula, os métodos de ensino, as regras, as penalidades e práticas de ensino, o processo avaliativo, os conteúdos a serem ensinados e as questões disciplinares. Desse modo, constata-se que a criação dos Grupos Escolares maranhenses, num primeiro momento (1903-1912), apresentou constante deficiência que contribuiu para que essas escolas fossem reconhecidas como "pseudo grupos", levando-os a serem completamente extintos em 1912 e somente em 1919 a serem recriados definitivamente.

Palavras-chave: Educação; Maranhão; História; Escolas de primeiro grau.

\author{
Diana Rocha da Silva \\ Doutoranda em Educação Escolar \\ pela Universidade Estadual \\ Paulista Júlio de Mesquita - \\ UNESP/SP - Brasil \\ rocha146@hotmail.com

\section{Cesar Augusto Castro} \\ Professor na Universidade \\ Federal do Maranhão - UFMA. \\ Doutor em Educação pela \\ Universidade de São Paulo - \\ USP/SP - Brasil \\ ccampin@terra.com.br
}

\section{Para citar este artigo:}

CASTRO, Cesar Augusto; SILVA, Diana Rocha da. A institucionalização dos grupos escolares no Maranhão. Revista Linhas. Florianópolis, v. 17, n. 33, p. 284-308, jan./abr. 2016. 


\title{
The institutionalization of the school groups in Maranhão
}

\begin{abstract}
This paper presents the history of the school groups in Maranhão deployed from 1903 focusing on the institutionalization process, education, exams, school attendance, supervision, duties and rules, which should be obeyed by students and teachers. It explains the main structural features that determine the extinction of these schools in 1912. The methodology is based on research literature, emphasizing the studies of Vidal (2006, 2007), Faria Filho (2006, 2007), Souza (2006, 2007, 2008, 2010), Motta (2006), Saldanha (1992); then, we turn to documentary research prioritizing the identification, selection, analysis and description of the Normal School documents (19031912) and Secretaria Geral da Instrução Pública Maranhense (1906-1910); reports of the Education delegates and inspectors (1903-1911); letters; invoices for the purchase of materials; photographs; reports of the State Governors (1903-1912), and frequency and grade list of students and analysis of the School Groups Bylaws in order to understand how the organization was established pedagogical work, the curriculum, the establishment of school hours, teaching methods, rules, penalties and teaching practices, the evaluation process, the contents to be taught, disciplinary matters. Thus, the creation of the Maranhão School Groups, at first (1903-1912), presented constant disability that contributed to these schools were recognized as "pseudo groups" causing their complete extinction in 1912.
\end{abstract}

Keywords: Education; Maranhão; History; Primary grade schools. 


\section{A institucionalização dos grupos escolares no Maranhão}

Os discursos em torno da criação dos Grupos Escolares em terra maranhense remontam a um contexto educacional em descrédito, fruto de várias ações políticas desvinculadas de sua realidade e que, na sua concretude, não puderam ou não tiveram condições de realizar a maioria das determinações preconizadas nas leis e regulamentos. Em vários Estados, a implantação dessas Escolas se deu num momento de avaliação negativa do ensino, no que se refere aos métodos, à formação docente, ao ambiente escolar e às representações que se tinha das Escolas Primárias gestadas no âmbito público até então. Nesse processo, podem-se perceber mudanças que, aparentemente, pareceram repentinas, mas que, na realidade, foram frutos de causas múltiplas encenadas pelos discursos de uma elite dominante, imbuída do papel de promover um ensino geral, unitário e necessário à consolidação de determinados propósitos.

No Maranhão, mesmo com inúmeras reformas no cenário educacional durante a última década dos oitocentos, o número elevado de analfabetos era uma questão preocupante para um Estado que possuía o codinome de "Atenas Brasileira"”. Aliado a isso, somavam-se a falta de escolas e a ausência de professores habilitados ao ensino. A alternativa sinalizada como saída ao combate do analfabetismo foi a adoção de um modelo de escolas graduadas. Sua primeira finalidade era contribuir para a consolidação dos ideais de ordem e progresso, utilizando a educação para isso (SOUZA; FARIA FILHO, 2006). Esses grupos representavam a inovação em educação, símbolo de modernidade no ensino, "[...] em sintonia com a expectativa em relação ao desenvolvimento social e econômico" (SOUZA, 2009, p. 30).

A Reforma da Instrução Pública realizada em São Paulo por Caetano de Campos, em 1890, serviu como referência para que outros estados modificassem, ou também criassem, regulamentos para a reestruturação da Instrução Pública Primária. Sua ênfase recaía na possibilidade de agrupar, em um mesmo espaço físico, várias escolas isoladas,

\footnotetext{
* Mestre em Educação pelo Programa de Pós-Graduação em Educação - UFMA.

${ }_{1}$ Apelido herdado em virtude do Estado, no início do século XX, contar com um grupo de literatos maranhenses reconhecidos nacionalmente. São Luís foi um dos locais que apresentou intensa atividade intelectual no Período Imperial Brasileiro. Segundo Martins (2008), não somente São Luís mereceu, ao longo do século XIX, o codinome de "Atenas Brasileira"; várias outras "Atenas" surgiram em outras províncias e capitais do país - Fortaleza, Olinda, Recife, Salvador, Rio de Janeiro.
} 
fato que facilitava a fiscalização e avaliação do ensino, além de estruturá-lo gradualmente em séries e na elaboração racional do currículo. Os Grupos Escolares, segundo Souza e Faria Filho (2006), fortaleceram as bases do regime republicano na última década do século XIX; os primeiros estados a aderirem a esse projeto inovador foram São Paulo, Pará e Rio de Janeiro. Posteriormente, implantaram-se mais oito grupos, obedecendo à seguinte distribuição: Paraná e Maranhão (1903); Minas Gerais (1906); Bahia, Rio Grande do Norte e Espírito Santo (1908); e Mato Grosso (1910) (VIDAL, 2006).

No período de implantação e estabilização das bases republicanas, o cenário educacional maranhense não favorecia a consolidação dos ideais preconizados pela política vigente. Desse modo, pretendia-se criar uma representação de "Escola de Verdade" (VIDAL, 2006; SCHUELER, 2010) ou "Casas de Ensino", como denominou J. J. Seabra em mensagem publicada no Jornal A Pacotilha, ao criticar a Instrução Pública maranhense, salientando que a mesma "caminhava para trás; [...] [contrariando] a evolução natural a que deveria obedecer a este fato singular”. Como sugestão para solucionar tal problema, J. Seabra declarou que "bastaria apenas transformar com mão forte todas as atuais Escolas Primárias em verdadeiras Casas de Ensino, afastando do magistério, os pseudo professores, sem competência e sem amor ao trabalho" (JORNAL A PACOTILHA, n. 168, de 16 de julho de 1904, p. 4). Segundo ele, as novas Casas de Ensino deveriam inculcar valores para conter a resistência quanto à implantação do projeto político e, ao mesmo tempo, contribuir para o fortalecimento das bases desse sistema, por meio da valorização dos símbolos nacionais, respeito às autoridades e defesa da moral e dos bons costumes.

Para transformar tal realidade e garantir a concretização dos intentos republicanos, Alexandre Collares Moreira Junior, governador do Estado (1902-1906), autorizou a conversão de seis escolas estaduais, localizadas no perímetro de São Luís, em dois Grupos Escolares, cada um composto por três unidades (Lei $n^{\circ} .323$ de 26 de março de 1903 ) regulamentados em 1904 , pelo decreto $n^{\circ} .36$, de $1^{\circ}$ de julho.

Art. 1 - Ficam instituídos nesta cidade dois grupos escolares, compondose cada um deles por três escolas de instrução primária, mantidas pelo Estado. 
Art. 2 - Os grupos escolares serão de regime misto e denominar-se-ão Primeiro Grupo Escolar e Segundo Grupo Escolar, e funcionarão nos edifícios que pelo governo lhes forem designados.

Art. 3 - O programa do ensino que nele será ministrado abrangerá, como na Escola Modelo Benedito Leite, os Cursos Elementar, Médio e Superior, e será lecionado observando-se os métodos seguidos neste último Instituto.

Art. 4 - Além desses cursos, terão os Grupos Escolares um outro especial, consagrado ao trabalho manual para as alunas e executarão jogos e exercícios ginásticos próprios a formar e desenvolver a educação física.

Art. 5 - As cadeiras que constituem os grupos escolares denominam-se primeira, segunda e terceira cadeira, correspondendo a primeira ao curso elementar, a segunda ao médio e a terceira ao curso superior (MARANHÃO. Decreto n. $36,1^{\circ}$ de julho de 1904).

Para manutenção dessa estrutura - rígida e inflexível - foi designado como diretor dos Grupos Escolares no Maranhão o Sr. Barbosa de Godóis, que neste período ocupava o mesmo cargo na Escola Normal e na Escola Modelo. Dentre suas atribuições, destacavase a incumbência de organizar, fiscalizar, dirigir e coordenar o ensino e outras atividades educativas (em sua maioria disciplinares) realizadas nesses recintos, como, por exemplo, a disciplina, a ordem e o respeito, além dos serviços do porteiro, do servente, os horários de aula e a assinatura do livro de ponto.

O professor Barbosa de Godóis foi o responsável pela elaboração do primeiro Regimento Interno dos Grupos e, em 9 de junho de 1904, submeteu-o para a aprovação do governador Alexandre Collares Moreira Junior. O documento, após ser avaliado e aprovado, foi publicado no Jornal “O Estado do Maranhão” (JORNAL O ESTADO DO MARANHÃO, $n^{\circ}$. 9292, ano, XXXV, $1^{\circ}$ ago. 1904), o qual regulamentava as normas de funcionamento dos mesmos, como a definição dos horários de aulas, os conteúdos disciplinares, as normas para efetuação de matrícula, os processos avaliativos dos educandos, funções, direitos, deveres e penalidades para alunos e funcionários.

Segundo o governador Collares Moreira, "a criação deste estabelecimento foi uma medida de grande alcance para o ensino primário, que não só melhoraria consideravelmente o método adotado, como se acha sujeito de uma fiscalização mais pronta e eficaz por parte do Diretor da Escola Normal” (MARANHÃO. Mensagem apresentada ao Congresso do Estado em 16 de fevereiro de 1905, pelo Exmo. Sr. Coronel 
Alexandre Collares Moreira Junior, 1905). No interior do Estado, a proposta de implantação dessas escolas surgiu a partir da Lei $n^{\circ}$. 363, de 31 de março de 1905, incentivada pelos discursos de João Nepomuceno de Sousa Machado, Inspetor Geral de Instrução Pública e Diretor do Liceu, que enviou a Collares Moreira a seguinte mensagem: “[...] o ensino primário tem sido o objeto de atenção dos poderes públicos, todavia a maioria das escolas do interior não apresenta o menor grau de prosperidade" (MARANHÃO. Mensagem apresentada ao Congresso do Estado em 16 de fevereiro de 1905, pelo Exmo. Sr. Coronel Alexandre Collares Moreira Junior, 1905). Tal realidade deveria ser mudada urgentemente, uma vez que o modelo de Escola Estadual graduada já havia sido criado em São Luís, por isso, era necessário expandi-lo para outras localidades do Estado. A interiorização desse projeto se deu inicialmente no município de Rosário, em 20 de abril de 1906. Nesse mesmo ano, instalou-se um Grupo Escolar na cidade de São Bento, criado em 31 de março, e em 1909 foi criado o Grupo Escolar de Codó. A seguir, abordaremos os principais aspectos que contribuíram para a remodelagem dessas escolas no Maranhão.

\subsection{O ensino nos grupos escolares}

Um dos símbolos de eficiência dos Grupos Escolares foi marcado pela fixação do período de matrícula. Se antes os responsáveis pelos educandos tinham o costume de procurar, a qualquer tempo, as instituições Públicas Primárias para o registro dos seus filhos, com a criação dos Grupos esse período ficou restrito de 2 a 25 de janeiro. Havendo procura, este prazo poderia ser estendido por mais 20 dias consecutivos.

Para efetuar a inscrição, os pré-alunos teriam que atender aos seguintes critérios, conforme Art. 7 do regimento interno:

a) prova de já ter sido a criança vacinada, bastando para a satisfação dessa exigência e inspeção das cicatrizes da vacina, feita pela mesma professora;

b) declaração da idade exata ou presumível da criança com mais de 6 anos e menos de 12, havendo a dúvida, que surja a prova pelo aspecto, verificado pela professora, a menos que pelo interessado seja exibida a certidão de idade; 
c) a afirmação que ela verificará pelo aspecto da criança de não sofrer esta de moléstia contagiosa, cumprindo-lhe exigir atestado médico, quando tenha a menor suspeita a respeito (MARANHÃO. Regimento Interno dos Grupos Escolares, 1904).

Esses critérios assumiam um caráter excludente, na medida em que restringiam o acesso para aqueles que cumprissem obrigatoriamente todos os requisitos. A determinação da vacina e a constatação do aspecto físico saudável das crianças eram duas das condições mais difíceis de serem cumpridas, pelo fato de que no Maranhão, no início do século XX, as condições salubres de água, luz e esgoto eram raras, contribuindo para a frequente infestação por doenças contagiosas.

O hábito de lavar as mãos, cortar as unhas, pentear os cabelos e portar roupas limpas eram preocupações que muitas famílias não se davam conta que precisavam exercitar. Em vários artigos do Regimento Interno dos Grupos Escolares (1904), esses aspectos eram constantemente mencionados como obrigatórios para a efetivação da matrícula e como deveres a serem cumpridos ao longo do Curso, caso contrário, eram alvos de punição severa, sendo, inclusive, motivo para suspensão de alunos.

Nos Grupos Escolares, a subdivisão do ensino em classe, turmas e graus era efetuada logo nos primeiros dias de aulas, quando o professor, responsável direto pelo ordenamento dos alunos, observava-os e classificava-os em seções, de acordo com a sua instrução: os mais e os menos desenvolvidos, os mais ativos, os mais atentos, os de raciocínio mais rápido, os mais lerdos, os mais inquietos e os mais difíceis de serem domesticados. Essa classificação também era efetuada após os exames avaliativos, quando se poderia definir e julgar, com mais certeza, o grau de adiantamento de cada aluno e ordená-los em uma das séries. "Essa organização consequentemente levou a escola a adotar critérios seletivos para matrícula em classe homogênea; supunha o favorecimento dos melhores em detrimento dos mais fracos" (SOUZA, 2006, p. 45).

As aulas tinham início às nove horas e finalizavam as treze exatamente, exceto quando houvesse trabalhos manuais para as meninas, cujo horário encerrava-se às quatorze horas. O tempo destinado a cada disciplina era controlado pelos professores e funcionários. Aos serventes, cabia a incumbência de tocar o sino, indicando o momento 
de entrada e encerramento das aulas, do recreio e do descanso dos alunos, o que evidenciava todo um processo de ritualização existente no cotidiano escolar.

O ritual cotidianamente executado pelas professoras era iniciado a partir da chegada antecipada na escola, a fim de fiscalizar e vistoriar todas as dependências da instituição; inspecionar os alunos, examinando as mãos, unhas, roupas, cabelos e calçados, e verificar se estes apresentavam os critérios de higiene dispostos no Regimento Interno de 1904; assinavam diariamente o ponto antes de iniciarem as aulas; observavam o roteiro e o horário das disciplinas, e seguiam a orientação do Diretor da Escola Normal sobre a adoção de livros, compêndios e materiais de ensino.

Ao iniciarem as aulas, as professoras faziam a chamada dos alunos, marcando um “F” para os ausentes e um "P" para os presentes. Em seguida, toda a turma realizava o canto inaugural dos trabalhos de aula, geralmente com algum hino pátrio. Durante o período em que estes permaneciam na escola, tinham que se portar com "todo o respeito e guardar o maior silêncio; prestar toda a atenção às lições que estavam sendo dadas e não distrair seus companheiros; pedir licença à professora para se retirarem do estabelecimento, principalmente antes do fim das lições", quando alguma necessidade os obrigasse a isso (MARANHÃO. Regimento Interno dos Grupos Escolares, 1904). A despedida consistia no encerramento com cântico e com formação de fila. "A vigilância naturalmente não eliminou as quebras de condutas devidamente punidas" (AZEVEDO, 2009, p. 85).

A primeira classe abrangia os rudimentos do ensino e era indicada para aqueles que não tinham conhecimento de leitura, escrita e cálculo. Nesse nível, os professores possuíam uma das tarefas mais difíceis de ser concluída: a de moldar os hábitos das crianças, tirando-Ihes os maus costumes, tradições que diariamente eram praticadas em casa, como os modos de se sentarem, falarem, comerem e dialogarem com os adultos. Eram os professores quem os ensinavam a obedecer às regras da escola e a ter os cuidados com a higiene. É importante destacar que ao se referir à higiene escolar, não nos referimos apenas à limpeza pessoal do aluno, mas, também, ao cuidado com os materiais escolares: os cadernos dos alunos deveriam ser apresentados diariamente aos professores rigorosamente limpos, com a lição transcrita corretamente, utilizando os tipos de letras indicados pelos professores, sem rasuras, riscos, sujeiras, folhas dobradas; 
de igual modo, os outros recursos didáticos como livros, folhas, mata borrão, dentre outros, deveriam ser mantidos com total higiene.

\subsection{Método de ensino}

O método intuitivo fez parte das propostas de modernização do ensino elaboradas por Rui Barbosa, em 1883, época em que o governo brasileiro visava adotar medidas que remodelassem o contexto educacional. Como resultado, solicitou uma investigação sobre a situação da instrução pública no país. A partir desse diagnóstico, concluiu-se que as técnicas e conteúdos de ensino utilizados nas escolas primárias não estavam dando os frutos esperados, pois eram vistos como atrasados e inúteis. Frente ao cenário de mudanças políticas e econômicas pelo qual passava a sociedade brasileira, fazia-se urgente a adoção de táticas de ensino moderno que se diferenciassem do método memorístico, dominantemente utilizado no Brasil até o final do século XIX. Para Rui Barbosa, o método intuitivo se configurava “[...] como o elemento mais importante de toda reforma [...]. Somente ele poderia triunfar sobre o ensino verbalístico, repetitivo, enraizado à memória e nas abstrações inúteis, praticado nas escolas de primeiras letras" (SOUZA, 2009, p. 75).

Nas escolas maranhenses, esse ensino era defendido principalmente pelos políticos (Alexandre Collares Moreira, Benedito Leite, Arthur Quadro Collares Moreira, entre outros), que sempre discursavam em prol da instalação da nova metodologia de aprendizagem. Além disso, criavam leis e decretos para determinar o uso do método nas Escolas Públicas Primárias do Estado. Alexandre Collares Moreira Junior, por exemplo, no ano em que determinou a criação dos Grupos Escolares em São Luís, ressaltava que o Estado passava por inúmeros problemas de ensino, e que essa realidade se dava, principalmente, em função da forma pela qual o ensino era ministrado e da má formação de professores.

Diante dessa constatação - implantar o ensino intuitivo -, Barbosa de Godóis foi pessoalmente a São Paulo, em 1904, a fim de aprender essa nova técnica e transmiti-la aos seus alunos da Escola Normal. Segundo o Art. $8^{\circ}$ do Regimento Interno dos Grupos 
Escolares maranhenses (1904), as professoras deveriam assistir aulas duas vezes ao mês, a fim de compreenderem as práticas de ensino desenvolvidas na Escola Modelo. Essas aulas seriam ministradas pelo próprio Diretor.

Apesar dessas orientações, muitos professores desconheciam a forma correta de transmitir os conteúdos aos seus alunos, não havendo uniformidade; na dúvida, recorriam as suas próprias metodologias. Os exames eram compostos por provas gráficas, orais e práticas. Esta última era aplicada apenas nas disciplinas de ensino objetivo, como física, química, música, forma, tamanho, prendas femininas e educação física.

\subsection{Corpo docente}

No Maranhão, as Escolas Estaduais eram vistas como ineficientes, devido, entre outros aspectos, à ausência de um corpo docente especializado que fizesse uso de novos métodos de ensino. Dentre os pré-requisitos para o exercício do magistério, além dos princípios da moralidade, nos Grupos Escolares era exigida a competência de saber ensinar, habilitação concedida pela Escola Normal, de acordo com o disposto no Art. 47 do Regimento Interno dos Grupos Escolares:

$1^{\circ}$ - ser cidadão brasileiro no gozo de seus direitos civis e políticos;

$2^{\circ}$ - nunca haver sido convencido de culpa infamatória e nunca haver sofrido pena alguma por crime infame;

$3^{\circ}$ - ter moralidade;

$4^{\circ}$ - possuir instrução profissional;

$5^{\circ}$ - não sofrer de moléstia infecto-contagiosa repugnante, repulsiva ou que, como a gagueira e surdez impossibilite para o magistério;

$6^{\circ}$ satisfazer previamente na parte que Ihe for relativa, a todas as prescrições e exigências constantes dos regulamentos especiais de cada um dos cinco ramos do ensino público. (MARANHÃO. Regulamento da Instrução Pública, 1896, p. 4, grifo nosso)

A docência nos Grupos Escolares foi se definindo como um campo preferencialmente constituído pela presença feminina. Por todo o país, "[...] a mulher passava a deixar sua marca na educação escolar" (AZEVEDO, 2009, p. 81). Apesar do predomínio das mulheres, apareceu a figura de Luís Viana, que era professor e secretário 
do Grupo Escolar de São Bento, e de Francisco Ribeiro, professor de um dos Grupos da capital. Tanto em São Luís como em Rosário, São Bento e Codó, não foi aberto nenhum concurso para a contratação de professores no ano de criação, como já mencionado anteriormente, por isso, as professoras foram transferidas das Escolas Estaduais para iniciarem os trabalhos de docência no Primeiro e Segundo Grupos Escolares.

Apesar da prevalência do público feminino, as professoras não eram postas em cargos de chefia. Todos os Grupos Escolares criados na primeira fase de sua Institucionalização (1903-1912) ficaram sob a administração do Diretor da Escolar Normal, o Professor Barbosa de Godóis. Esta última, não apenas no Maranhão, mas em outras regiões do país, configurou-se como uma instituição de formação profissional para as mulheres, ou seja, era a possibilidade de vislumbrarem uma carreira que não fosse a de dona de casa, mãe, esposa ou, quando muito, de professora de prenda doméstica.

Segundo Azevedo (2009), a presença dessas docentes não representava um benefício para os Grupos Escolares, principalmente pela existência de um forte rodízio de professoras e alunos que se agravava pelas constantes solicitações de licença para tratamento de saúde. Logo no primeiro ano de funcionamento, Corina Cardoso Maya, professora da Terceira Cadeira do Primeiro Grupo Escolar da Capital, solicitou, por meio do oficio $n^{\circ} .54$ de 1904, licença por tempo indeterminado, sendo substituída por Paschoa Galvão, professora da Primeira Escola Estadual, que assumiu a regência da cadeira vaga no Primeiro Grupo até que Collares Moreira solucionasse o impasse. Barbosa de Godóis orientou ainda que essa professora distribuísse os alunos da Escola Estadual pelos institutos que ofereciam a mesma modalidade de ensino (MARANHÃO. Secretaria da Escola Normal. São Luís, 13 de julho de 1904. of. 54).

\subsection{Infraestrutura dos grupos escolares}

Ao serem inaugurados os Grupos Escolares no Maranhão, também denominados Casas Escolas, o Governador do Estado (Alexandre Collares Moreira Junior), por meio do Art. 2, do Decreto $\mathrm{n}^{\circ} .36$, de $1^{\circ}$ de junho de 1904 , determinou que esses Institutos fossem instalados nos edifícios por ele designados. Sem verba para a construção de prédios, os Grupos Escolares ocuparam os espaços onde funcionavam a Primeira e a Segunda Escola 
Estadual, localizadas na Rua do Sol e Rua Grande, respectivamente. No início do século XX, essas ruas se configuravam como partes da importante zona comercial de São Luís.

$\mathrm{Na}$ primeira fase de sua institucionalização (1903-1912), os Grupos Escolares maranhenses foram instalados em prédios antigos que não apresentavam as especificações características do tipo de escola moderna, isto é, espaços propícios para a realização dos trabalhos pedagógicos e que, certamente, contribuíam para consolidar a imagem de Escola de Verdade, defendida pelos adeptos desse modelo (Benedito Leite, Collares Moreira, no campo político e entre os intelectuais, Antônio Lobo, Barbosa de Godóis, Ribeiro do Amaral e João Nepomuceno de Sousa Machado). De acordo com o Código Sanitário do Estado do Maranhão de 1904, era necessário obedecer às seguintes determinações estabelecidas para construção de edifícios escolares:

Art. 155 - Deverão ficar longe de hospitais, asilos, cemitérios, hospícios, quartéis, fábricas, prisões...

Art. 116 - Deverão ser construídas nos centros de população condensada, contudo será de rigor escolher ruas ou praças pouco concorridas e onde não haja aglomeração urbana.

Art. 117 - Deverão ficar sempre bem isoladas das casas mais próximas, evitando receberem influência.

Art. 118 - Na escolha do local para construção de um edifício escolar deve merecer muito cuidado a corrente dos ventos reinantes.

Art. 119 - O melhor plano para uma escola será aquele que lhe dê um só pavimento. (MARANHÃO. Código Sanitário, 1904)

Contudo, os Grupos Escolares maranhenses não garantiram todas as condições higiênicas necessárias à prevenção de doenças. O governo maranhense reservou apenas 1.800\$000 para o aluguel desses prédios na Capital e 350\$000 no Interior, recursos considerados insuficientes e que determinaram a instalação dessas escolas em edifícios que, nesse período (em 1908), já apresentavam inúmeras dificuldades estruturais, como vidraças quebradas, aspectos de escola antiga e mal cuidada.

Diante disso, Alexandre Collares Moreira Junior (1905), ao reconhecer o estado decadente dos prédios destinados a essas escolas, principalmente em relação ao edifício do Segundo Grupo Escolar da capital, ressaltou que se não fossem as más condições financeiras do Estado, lembraria como medida imperiosa a construção de prédios para as 
Instituições Públicas, que colocadas em casas nas quais faltavam quase todos os requisitos pedagógicos, não poderiam exercer satisfatoriamente a sua missão. $\mathrm{Na}$ realidade, os governantes tinham ciência de que se não houvesse maiores investimentos para a manutenção dessas escolas, certamente o estado de decadência se agravaria. $E$ foi o que aconteceu de acordo com o comentário a seguir:

Comunicando-me a secretária do Primeiro Grupo Escolar da Capital a absoluta falta de água neste estabelecimento, rogo-vos que vos digneis de mandar providenciar no sentido de ser feito pela respectiva companhia o reparo que se torna necessário no encerramento de água do referido estabelecimento. B. G. dir.(MARANHÃO. Secretaria da Escola Normal, 1907, of. 36)

Comunicando-me a secretaria do primeiro grupo escolar da capital achase bastante danificado o telhado do edifício em que funciona esse instituto, o que acarreta a quase impossibilidade de funcionamento das aulas nesta estação de chuva, solicito-vos providências no sentido de serem apurados naquela parte do referido prédio os concertos de cuja falta ele se recente. B. G. dir. (MARANHÃO. Secretaria da Escola Normal, 8 de fevereiro de 1908)

Diante dessa realidade, Arthur Collares Moreira autorizou, em 1907, o fechamento definitivo do Grupo, que já não era mais utilizado para aulas desde o início de 1905. A fim de superar esse desmantelo no cenário educativo de São Luís, esse governador abriu mão da administração do Segundo Grupo e a transferiu para a municipalidade por meio do decreto $n^{\circ} .66$ e de acordo com a lei $n^{\circ} .464$, de 13 de abril de 1907.

O Grupo passou a funcionar em $1^{\circ}$ de maio de 1907 . Ao ter suas aulas reabertas manteve a mesma estrutura organizacional de sua origem e seguia as mesmas recomendações dispostas no Regimento Interno criado em 1904 (MARANHÃO. Códice de 2 de maio de 1907). Apesar de ter sido restabelecido em 1907, o município também não dispensou maiores atenções quanto à manutenção do Grupo. Os mais atingidos com essa falta de estruturação foram os alunos que, frequentemente, eram deslocados para assistirem aulas nos outros estabelecimentos de ensino, como a Escola Modelo e as Escolas Estaduais mistas ou as Escolas isoladas. 


\subsection{Fiscalização}

A fiscalização no ensino público visava coibir alguma irregularidade existente nas escolas, sejam elas praticadas por professores, alunos ou qualquer outro funcionário. Em relação à fiscalização dos professores dos Grupos Escolares, a vigilância se fazia necessária especialmente por impedir que os conteúdos disciplinares fossem alterados e para garantir a aplicação do método de ensino sugerido nos Regulamentos da Instrução Pública do Estado.

Para a fiscalização nos Grupos Escolares foi designada uma comissão formada por professores da Escola Normal e por pessoas escolhidas pelo Diretor desse Instituto de Formação, os quais estavam incumbidos de visitar os Grupos em ocasiões não informadas, com a finalidade de surpreenderem os professores na prática de alguma irregularidade.

Nessas visitas, a comissão deveria verificar o número de alunos matriculados em cada classe e suas respectivas frequências; a presença ou ausência de professores em suas determinadas salas; o trabalho de cada um dos funcionários; a aplicação do método intuitivo, os exercícios físicos, os horários de aulas e as prendas femininas. Além disso, a comissão relatava a situação dos prédios, dos materiais didáticos e as condições salubres existentes ou não nas escolas (AZEVEDO, 2009).

A comissão designada para fiscalizar os Grupos Escolares do Maranhão tinha o direito de advertir os professores publicamente e de verificar as médias diárias dos alunos, a frequência e o aproveitamento referentes ao mês anterior. Os Inspetores de ensino eram os responsáveis legais pela ordem e disciplina dos discentes, pela fiscalização do serviço dos serventes e do porteiro, e pela vigilância permanente das atividades realizadas pelos Grupos em dias festivos.

Para o registro formal do cotidiano escolar, foram criados dispositivos que regulassem o funcionamento diário das classes: livro de ponto dos funcionários e alunos, matrícula, termo de visita e de exames. Todas as anotações feitas nesses suportes serviam para avaliar o andamento dos trabalhos desenvolvidos nos Grupos Escolares. Nas visitas realizadas pela Comissão de Fiscalização da Instrução, os professores quase 
sempre se sentiam ameaçados pelos Inspetores ou Delegados de ensino, pois a diminuição da frequência diária dos educandos era considerada culpa desses profissionais, que eram julgados por omissão ou falta de cumprimento do dever.

\subsection{Cotidiano escolar}

Alguns fatos marcaram o cotidiano dos Grupos Escolares, como as festas cívicas, a abertura e o encerramento do ano letivo, as férias escolares, os exames e a promoção de alunos. Por meio desses eventos foi possível estabelecer conexões e compreender os aspectos culturais vivenciados no interior dessas escolas. Azevedo (2009, p. 32) esclarece que "[...] a cultura escolar da modernidade traz em si um grande objetivo, o de servir como fonte de um padrão cultural com vistas a uma reorganização de comportamento que deve se orientar basicamente pelo disciplinamento dos corpos e pela consciência de um povo". Nesse contexto, era o professor o responsável por conquistar a confiança e o respeito das crianças com atitudes amistosas, motivando-as a frequentarem as aulas.

Os alunos deveriam comparecer à escola no horário determinado para a abertura das aulas, pontualmente às nove horas da manhã; os alunos eram organizados em fila, à espera do comando dos professores, liberando-os para a entrada. Ao entrarem nas salas, os discentes esperavam de pé a chegada da professora e apenas se sentavam mediante a sua ordem. Se a professora detectasse ou desconfiasse que algum aluno possuísse indício de doença, este era impedido de adentrar a escola, e, se entrasse, ao ser constatado tal fato, o mesmo teria que se retirar da classe e o ocorrido deveria ser comunicado ao médico escolar. Segundo o Art. $62 \S 6$ do Regimento, as professoras mandavam se retirar da aula qualquer aluno que apresentasse moléstia contagiosa, sem a possibilidade de admiti-lo enquanto não fosse reestabelecido. No Art. 29 desse mesmo Regimento, a professora que percebesse que a "ausência do aluno, depois de respondida a chamada, [pudesse] ter sido motivada por moléstia, deveria isso constar no livro de frequência adiante do nome do aluno, na casa correspondente à nota do dia, servindo para designála as duas iniciais - R. D. [(Registro de doença)]”.

Os horários de aula eram sinalizados por meio do toque da sineta. Cada disciplina possuía um momento determinado para o ensino, e, caso fosse alterado, o professor da 
respectiva cadeira pagaria uma multa de $10 \$ 000$ a 50\$000. Esse horário era regulado pelo relógio de parede, dispositivo indispensável para o controle dos trabalhos docentes.

Azevedo (2009) afirma que os alunos, professores e diretores viviam ritualisticamente o dia a dia nos Grupos Escolares. A organização das filas; a fiscalização diária das vestimentas, das mãos e unhas; o badalar do sino (que indicava o horário de entoar os hinos antes da entrada na escola); o toque da sineta (que informava o início das aulas, do recreio e do descanso); os olhos atentos dos professores à procura de alguma anormalidade; a seriedade das palavras dos professores, prontos para corrigirem qualquer falta de ordem e desrespeito, eram gestos que indicavam a ritualização vivenciada pelo corpo docente no ambiente escolar.

Apesar da incorporação de práticas culturais se configurarem como símbolo de eficiência, essa imagem nos grupos maranhenses, aos poucos, foi sendo mudada devido a não manutenção de todas essas características. A carência de estrutura adequada e a não concretização dos métodos de ensino - intuitivo -, que privilegiavam a adoção de materiais didáticos como suportes para os alunos aprenderem na prática, contribuíram para que a instalação dessas escolas não desse certo (pelo menos ao que se refere à primeira fase de sua institucionalização), em terras maranhenses.

\subsection{Os exames escolares}

A aplicação dos exames nos Grupos Escolares era efetuada a partir de uma rede de ritualização, previamente planejada, em que as definições do dia, hora e comissão avaliadora eram regularizadas em lei. Todos que participavam desse ato público carregavam consigo a sensação de estar participando de uma das cerimônias mais importantes da escola. O ritual de passagem contava com a presença de autoridades do ensino, como o Secretário Geral da Instrução Pública, professores normalistas e o Diretor do Grupo. Os exames escolares consistiam na qualificação de uns e exclusão de outros, pois, por meio deles, classificavam-se os alunos habilitados, os inabilitados, os que eram aprovados com distinção e os simplesmente aprovados (AZEVEDO, 2009). 
Os exames nos Grupos Escolares maranhenses eram aplicados por uma mesa examinadora designada pelo Governador do Estado, e constituída em cada classe por um presidente, pela professora da respectiva cadeira e por outra professora normalista indicada pelo diretor da Escola Normal. Ao ser finalizado, a professora de cada classe lavrava o termo competente em livro especial, o qual seria assinado pela mesa examinadora e pelas autoridades superiores de ensino que estivessem presentes no ato da aplicação da prova (MARANHÃO. Regimento Interno dos Grupos Escolares, 1904, Art. 38). É interessante ressaltar que, apesar da atenção dada aos exames finais, os alunos eram avaliados diariamente. O professor utilizava o livro de ponto do aluno para atribuir notas por comportamento, participação nas aulas (ao solicitar que os alunos praticassem a leitura em voz alta, cópias de textos, respostas a alguma pergunta oral ou demonstradas no quadro negro, e práticas de lições de coisas). Os alunos do último ano da terceira cadeira, que fossem aprovados, receberiam carta de habilitação assinada pela mesa avaliadora dos exames, atestando a conclusão do Curso Primário. Eram graus de julgamento das lições, segundo o Art. 31 do Regimento Interno dos Grupos Escolares: 10 equivalente a ótima; 7 a 9 - equivalente a boa; 4 a 6 - equivalente a sofrível; 1 a 3 equivalente a má.

Os exames começavam pela Terceira Cadeira. As provas versavam sobre os conteúdos ensinados no decorrer do ano, e eram aplicadas de forma escrita, prática e oral. A primeira durava cerca de três horas e o aluno tinha direito a mais quinze minutos, caso fosse necessário; as práticas também poderiam ser executadas em, no máximo, três horas, e, no mínimo, vinte minutos. No ato da realização dos exames, o aluno era impedido de manter qualquer contato com os colegas de classe ou com a mesa examinadora, imposição que nem sempre era possível de ser evitada, mesmo quando os professores mais severos tentavam impedir tal ato por meio da vigilância. Alguns mestres tinham o costume de usar óculos escuros durante as avaliações escritas, prática que nos faz inquirir a existência de alguma tática por parte dos discentes em burlar algumas dessas regras (FERRO, 2010).

De acordo com o Art. 41 do Regimento dos Grupos Escolares, teriam prova gráfica e oral as seguintes disciplinas: língua materna, cálculo, lugar e instrução cívica; prova oral e prática: ensino objetivo na parte relativa à física e química; prova ao mesmo tempo 
prática e oral: ensino objetivo na parte relativa às ciências naturais, música, forma e tamanho; apenas prova oral: os exercícios orais e o canto; apenas prova gráfica: desenho; e apenas prova prática: prendas femininas e educação física.

Considerava-se aprovado com distinção aqueles alunos que atingissem nota igual a 10; aprovado plenamente os que alcançassem nota entre 7 e 9; simplesmente aprovados os alunos que tivessem suas notas variando entre 4 e 6; e reprovados aqueles que não atingissem nota superior a 3 e recebessem o julgamento de má ou sofrível. Além disso, o aluno deveria comprovar a ausência de qualquer irregularidade cometida e não apresentar mais de 90 faltas por ano (MARANHÃO. Regimento Interno dos Grupos Escolares, 1904). Cumprindo esses critérios, os alunos receberiam a carta de promoção que dava acesso às outras turmas, ou a carta de habilitação, que atestava a conclusão do Curso.

Outro fator para a redução do número de matrículas e aprovações foi a constante retirada de alunos das escolas depois que aprendiam as primeiras letras, fato que ocasionava significativa evasão. Na Terceira Cadeira do Segundo Grupo não houve alunos aprovados porque, no mesmo período, eles foram agregados ao Primeiro Grupo. Esse fato se deu por razões estruturais do grupo. Assim, somando as duas cadeiras dos dois Grupos, o número total de aprovados correspondeu a 38\% de um total de 34 alunos matriculados; apenas um aluno concluiu o Curso no final de 1904.

Se no ano de sua implantação (1904) houve 217 alunos matriculados nos dois Grupos Escolares, em 1909 esse número diminuiu para 141, representando uma queda brusca de aproximadamente 35,02\%. Essa diferença talvez possa ser compreendida a partir da análise dos ofícios encaminhados por Barbosa de Godóis ao Governador do Estado (Arthur Quadros Collares Moreira), nos quais ele enfatizava o estado decadente dos Grupos Escolares, especialmente em relação à estrutura dos edifícios em que as escolas funcionavam e à falta de manutenção dos mesmos. Tal realidade ocasionou o fechamento do Segundo Grupo no período de 1905 a 1907, sendo restabelecido neste último ano, porém sem o devido prestígio.

Quando observamos os índices de aproveitamento das cadeiras dos grupos, constatamos que na Terceira Classe não houve alunos matriculados e, consequentemente, nenhuma submissão aos exames anuais. A ausência de alunos 
ocorreu pelo fato da respectiva cadeira ter sido distribuída para outros Institutos de ensino dessa mesma modalidade, já que as condições estruturais do Segundo Grupo Escolar, em 1909, eram precárias (MARANHÃO. Secretaria da Escola Normal, 1909).

\subsection{Frequência nos grupos escolares}

A frequência nos Grupos Escolares Maranhenses, durante a primeira década de sua existência, passou por vários períodos de instabilidade. Logo no primeiro ano, a procura por vagas foi bastante expressiva. A crença nesse modelo de escola fazia com que muitas famílias preferissem matricular seus filhos nos Grupos Escolares às Escolas Estaduais ou Mistas. Motta (2006) explica que essas vagas, antes destinadas aos filhos das famílias menos abastadas, foram sendo preenchidas pelos filhos dos doutores, engenheiros e médicos.

A preferência por esses estabelecimentos de ensino correspondia aos modelos que eram apregoados como símbolo da modernidade educativa, "[...] em substituição ao passado imperial, ultrapassando [as] representações das escolas isoladas" (SOUZA; FARIA FILHO, 2006, p. 26). A eficiência e utilidade desses modelos se fundamentavam no fato de apresentarem uma organização mais lógica e definida, como: edifício próprio; classes homogêneas; ensino simultâneo e intuitivo; séries graduadas e sequenciais; estabelecimento de exames finais; presença de docentes e de corpo de funcionários; ampliação do currículo; controle do tempo, da frequência; e definição de períodos de matrícula. Esses aspectos

[...] fundaram uma representação de ensino primário que não apenas regulou o comportamento, reencenando cotidianamente, de professores e alunos no interior das instituições escolares como disseminou valores e normas sociais e educativas. [...] da interação da defesa da escola laica, da liberdade de ensino, da obrigatoriedade da instrução elementar, do direito à educação e do dever do Estado e da família. (VIDAL, 2006, p. 10)

No Maranhão, a representação dos Grupos Escolares como "Escola de Verdade" nasceu a partir do discurso republicano no final do século XIX, que viam a educação 
pública como um instrumento capaz de mudar determinada realidade, e que se sustentou até os primeiros dois semestres após sua criação. Aos poucos, essa representação foi sendo substituída passando a ser vista como ineficaz, já que transformar esse discurso em prática não dependia apenas de elogios ou crenças na adoção de modelos educacionais, que eram importados de outra realidade. Havia a necessidade de adaptá-lo à realidade brasileira e, em especial, à maranhense.

Essa ineficácia poderia ser melhor visualizada no Segundo Grupo Escolar, criado em 1904 e que funcionou por apenas seis meses (a abertura das aulas aconteceu em agosto de 1904 e o encerramento em dezembro do mesmo ano). Após esse período, o Grupo se manteve fechado até 1907 e, durante esse tempo, os alunos passaram a assistir as aulas no Primeiro Grupo Escolar. Ao criticar a criação dessas instituições, denominando-os de "Pseudo Grupos Escolares", Antônio Lobo comentou:

E pra provar dessa última assertiva basta lembrar-vos a criação dos pseudos grupos escolares, cada um deles amontoados numa sala única, de capacidade seis vezes inferiores à estritamente requerida e confiado a professores em número 3, 4 e 5 vezes [...] além do que lhe competia. (MARANHÃO. Inspetoria Geral da Instrução Pública e Diretoria do Liceu maranhense. of. $n^{\circ}$. 5, São Luís, 14 de janeiro de 1911)

A crítica de Antônio Lobo recaía especialmente em dois aspectos: a adoção de modelos estrangeiros, conceituado por ele como inovestas, quer dizer, puro modismo que dando certo em outras realidades, não tiveram a mesma experiência em terra maranhense. A baixa frequência dos alunos também era influenciada, principalmente, pelos seguintes fatores:

1) Fechamento do Segundo Grupo Escolar;

2) Descrédito da sociedade ludovicense nesse modelo de ensino;

3) Transferência de professores e alunos para outros institutos;

4) Não cumprimento dos programas de ensino;

5) Falta de estrutura dos prédios;

6) Insuficientes recursos destinados à manutenção dos Grupos (Capital e Interior). 
Segundo Lobo (1910), a diminuição na frequência ocorria também em "[...] consequência da seleção que foi havendo de ano em ano nas turmas e classes e do costume, entre nós reinante, de serem em parte retirados os alunos das escolas, logo que eles adquirem uma certa instrução". Segundo Lobo, "por vezes, para que a classe superior não fique sem alunos, as professoras respectivas se têm interessado pessoalmente com as famílias dos alunos, no sentido de os manterem no instituto, tem sido, entretanto muito limitada essa frequência" (MARANHÃO. Secretaria da Escola Normal, 1909).

\section{Conclusão}

Com a proclamação da República, aflorou-se a necessidade dos Estados se adequarem aos ideais de civilidade e modernidade. No Maranhão do final do século XIX, a incorporação desses intentos resultou na criação de cinco leis (Reforma José Tomaz de Porciúncula, de 1890; Reforma Lourenço de Sá, de 1891. A Reforma Cunha Martins. Reforma Benedito Leite, de 1895, Regulamento da Instrução Pública do Maranhão, 1896, e Reforma da Instrução Pública, 1899), as quais estabeleciam reformas no campo educacional. Tais leis priorizaram a abertura de cadeiras isoladas e a obrigatoriedade do ensino, porém esses dispositivos não se ativeram aos repasses de recursos que seriam aplicados na melhoria do ensino público primário. A maioria das escolas funcionava com inúmeras dificuldades, dentre elas a ausência de professores formados pela Escola Normal, a falta de recursos didáticos, a inexistência de prédios próprios para a instalação das escolas e de mobiliário escolar necessário ao bom andamento do ensino.

Em relação ao ensino, constatamos que, em alguns momentos, tanto os Grupos Escolares da capital, quanto os implantados no interior, não conseguiram desenvolver o ensino graduado em virtude da falta de professores que, em muitos casos, eram transferidos ou nomeados para assumirem outras cadeiras ou funções nas demais instituições públicas.

A docência nos grupos do Maranhão foi consagrada pela presença do público majoritariamente feminino, tanto no interior como na capital. Mesmo assim, o cenário 
revelava que o poder masculino ainda imperava nas escolas maranhenses, pelo menos ao que se refere à primeira fase de sua institucionalização. Esse fato é bem notório nos grupos do Maranhão, onde todas as decisões estavam centralizadas em uma só pessoa, Barbosa de Godóis, responsável legal por essas escolas durante toda a primeira fase (1903-1912).

O respeito, a disciplina, a obediência, os valores patrióticos e cívicos eram práticas cotidianamente reforçadas pelos professores nos grupos escolares. Consideramos, porém, que muitas dessas práticas não foram aceitas com parcialidade pelos educandos, pois as disposições declaradas no regimento interno dos grupos escolares de 1904 revelam que, ao defender o controle exacerbado, a vigilância, a fiscalização e as penalidades entre os alunos, havia uma considerável desordem nesse ambiente escolar, ou a possibilidade de tê-la. A declaração das atitudes, consideradas fora do padrão de normalidade, deveria ser severamente punida. Tais aspectos nos fazem crer que as crianças nem sempre obedeciam às imposições e às regras de convivência interna nessas escolas. A obrigatoriedade do silêncio e do comportamento dos alunos na faixa etária de 6 a 12 anos, caracterizada pela inquietude e curiosidade, eram costumes difíceis de serem controlados.

Em relação à infraestrutura, as dificuldades não demoraram a surgir. Logo no final do primeiro semestre de iniciação dessas escolas, o segundo grupo escolar foi fechado por falta de condições para o seu funcionamento. Goteiras, banheiros quebrados, portas sem trancas e vidraças danificadas eram alguns dos fatores que demarcavam a precariedade dessas escolas durante sua primeira fase de implantação. De 1905 a 1912, eram frequentes as críticas de Barbosa de Godóis sobre as péssimas condições em que se encontravam os grupos escolares do Maranhão, chegando, até mesmo, a afirmar que nestas escolas faltava quase de tudo. Esses fatos levaram Antonio Lobo, Inspetor da Instrução Pública, a considerá-los como pseudos grupos, como já dito anteriormente. É importante sinalizar que, neste primeiro período de sua instituição, os recursos destinados à manutenção não sofreram elevação no valor, dificultando assim possíveis melhorias.

Mediante essas reflexões, podemos considerar que o processo de institucionalização dos Grupos Escolares no Estado do Maranhão não resolveu o 
problema histórico da educação, que ainda hoje apresenta seus sinais negativos. O fato de adotar esse modelo de ensino não solucionou o quadro deficitário de analfabetismo que vinha se arrastando desde a colônia.

Dessa forma, constatamos que a história dos Grupos Escolares maranhenses é marcada por duas iniciativas, ambas incentivadas pelos governantes do Estado e tendo como característica básica o ideal de escola pública primária, a qual pudesse contribuir para a concretização dos princípios republicanos. A primeira fase, que se estendeu de 1903 a 1912, foi definida como período conturbado, precário e com inúmeras dificuldades que refutaram a imagem de escola moderna e eficaz, tão defendida e difundida pelos políticos e intelectuais maranhenses. A segunda, inicia-se a partir de 1919 a 1970, demarcando uma nova etapa para a modernização da educação pública no cenário maranhense. 


\section{Referências}

AZEVEDO, Crislane Barbosa de. Grupos escolares em Sergipe (1911-1930): cultura escolar, civilização e escolarização da infância. Natal, RN: UFRN, 2009.

FERRO, Maria do Amparo B. Cazuza e o sonho da escola ideal. São Luís: EDUFMA, 2010. 308 p.

JORNAL O ESTADO DO MARANHÃO. São Luís, nº 9292, ano, XXXV, 1 ago. 1904.

MARANHÃO. Regulamento geral da Instrução pública. São Luís: Tipografia a Vapor dos Frias, 1896.

MARANHÃO. Secretaria da Escola Normal. of. 36. São Luís, 6 fev. 1907.

MARANHÃO. Secretaria da Escola Normal. Título documento. São Luís, 3 jan. 1909.

MARANHÃO. Inspetoria Geral da Instrução Pública e Diretoria do Liceu Maranhense. Of. n. 5. São Luís, 14 jan. 1911.

MARANHÃO. Regimento Interno dos Grupos Escolares. São Luís, 1904.

MARANHÃO . Códice. Escola normal. Local, 7 maio 1907.

MARANHÃO. Código sanitário. São Luís, 1904.

MARANHÃO. Secretaria da Escola Normal, Título do documento. São Luís, 1904.

MARANHÃO. Regimento Interno dos Grupos Escolares, São Luís, 1904.

MARANHÃO. Mensagem apresentada ao Congresso do Estado em 16 de fevereiro de 1905, pelo Exmo. Sr. Coronel Alexandre Collares Moreira Junior, 1905.

MARANHÃO. Regimento Interno dos Grupos Escolares. São Luís, 1904.

MARTINS, Ricardo André Ferreira. Atenienses e fluminenses a invenção do cânone nacional. Anais do SETA, v. 2, 2008. Disponível em:

<http://iel.unicamp.br/revista/index.php/seta/articles>. Acesso em: 15 jul. 2011

MOTTA, Diomar das Graças. A emergência dos Grupos escolares no Maranhão. In: VIDAL, Diana Gonçalves (Org.). Grupos escolares: cultura escolar primária e escolarização da infância no Brasil (1893-1971). Campinas, SP: Mercados das letras, 2006.

PACOTILHA, JORNAL DA TARDE. São Luís, 16 de julho de 1904, n. 168, ano XXIV.

PACOTILHA, JORNAL DA TARDE. São Luís. Decreto n. 36. Local, 1 jul. 1904. 
SCHUELER, Alessandra Frota M. de. Escolas de verdade para a República do Brasil: os grupos escolares na Capital Federal. Disponível em:

<http:www.encontro2008.rj.anpuh.org/resources/content/anais>. Acesso em: 11 abr. 2010

SOUZA, Rosa de Fátima; FARIA FILHO, Luciano Mendes de. A Contribuição dos estudos sobre grupos escolares para a renovação da história do ensino primário no Brasil. In: VIDAL, Diana Gonçalves (Org.). Grupos escolares: cultura escolar primária e escolarização da infância no Brasil (1893-1971). Campinas, SP: Mercados das letras, 2006.

SOUZA, Rosa de Fátima; FARIA FILHO, Luciano Mendes de. Alicerces da pátria: história da escola primária no Estado de são Paulo (1890-1976). Campinas: Mercado das Letras, 2009.

VIDAL, Diana Gonçalves. Tecendo história (e recriando memória) da escola primaria e da infância no Brasil: os grupos escolares em foto. In: VIDAL, Diana Gonçalves (Org.). Grupos escolares: cultura escolar primária e escolarização da infância no Brasil (1893-1971). Campinas, SP: Mercados das Letras, 2006.

Universidade do Estado de Santa Catarina - UDESC Programa de Pós-Graduação em Educação - PPGE

Revista Linhas

Volume 17 - Número 33 - Ano 2016 revistalinhas@gmail.com 